The Iron Age $A 2-A B$ hill forts which were completed when excavated reveal the same civilization as the folk who inhabited other settlements marked by pits. The pits, however, are far too few to suggest that such hill-forts were either constantly inhabited oppida or concerned with urban civilization and industry. They were only built and inhabited for a short time during periods of unrest. On the other hand, both boundary ditches and hill-forts lead us to presuppose a substantial agricultural population living outside the farms in open settlements on low ground and on slopes close to water. In such settlements lived the greater part of the agricultural Iron Age $A 2-A B$ population.

\title{
ELECTRIC TUNNEL KILNS FOR FIRING PORCELAIN
}

$I^{\mathrm{N}}$ Electrotechnics, the journal of the Electrical Engineering Society of the Indian Institute of Science, Bangalore (S. India), of September, there is published an instructive paper by H. N. Ramachandra Rao, of the Government Porcelain Factory, Bangalore, discussing the use of an electric tunnel kiln for firing porcelain.

Until recently, the discontinuous coal-fired kiln, known as the round kiln, was generally used for firing hard porcelain. This type of kiln has certain inherent defects and demands great skill in handling. The coal used for such a kiln should have a high calorific value and must be free from impurities.

In using these round kilns, the ware is kept in saggars (refractory containers) which prevent the ware from direct contact with the flames, provide for economic filling and keep the ware free from strain. To obtain the maximum temperature of $1,350^{\circ} \mathrm{C}$. takes about 36 hours and the kiln has to cool for an additional 48-60 hours before being unloaded.

An important factor that enters into the correct firing of porcelain is the composition of the flue gases. In the round kiln it is very difficult to control the composition of the gases within desired limits on account of the unavoidable contamination or oxidation which takes place owing to the leakage of air into the kiln through combustion devices and holes or cracks that develop in a structure made of brick and fireclay when subjected to repeated heating and cooling. Besides, it is practically impossible to get a uniform distribution of heat inside this type of kiln.

The thermal efficiency of the kiln is very low, about 5-10 per cent, chiefly due to the wastage of heat from the hot gases, which are allowed to escape to the atmosphere at a high temperature. The working cost of such a kiln is again influenced by high labour charges, total holding capacity of the building and high cost of saggars.

These difficulties were to a great extent overcome by the introduction of fuel-fired tunnel kilns which are in more general use at present. There are two types of tunnel-kilns which are suitable for firing hard porcelain. In one type the products of combustion mingle with the ware; the most modern example is the Harrop kiln. The other is of muffled type, and is known as the Dressler kiln. The fuels in general use are natural gas or oil, and they are introduced with a small amount of air through highly refractory burner tubes. The tunnel is provided with a series of fire-places or gas burners on both sides and the goods to be fired are made to enter it on a chain of cars. The hot gases pass along the tunnel towards the end at which the goods enter, so that the ware is gradually heated as it passes towards the hottest part of the kiln. After having attained the maximum temperature required the ware travels on through the remainder of the tunnel, meeting in the journey a current of air travelling in the opposite direction. This air is heated by the cooling goods and gradually attains the maximum temperature of the kiln, thus ensuring the greatest efficiency of combustion. The goods on leaving the tunnel are almost cold.

The tunnel is built almost entirely of brick; lowgrade fire bricks are used in the zones of low temperature, and silica or carborundum bricks in the high temperature zone. Suitable expansion joints are provided in the structure. The draught which supports combustion is provided by an exhaust fan.

Although the fuel-fired tunnel kiln is an improve ment on the round kiln, it has certain drawbacks which can be eliminated by using the electric tunnel kiln. When the tunnel kiln is fuel-fired, the incoming ware is dependent for its preheating upon the outgoing combustion gașes, which heat the upper portions of the ware more than the lower. This not only makes an even rate of preheating over a given crosssection practically impossible, but also limits the rate of preheating to the speed at which the coldest portion becomes sufficiently hot to advance into the high-temperature zone. In the case of an electric tunnel kiln, on the other hand, the absence of moving atmosphere makes an easier recuperation possible in a continuous operation by having two lines of the ware in the same or adjacent tunnels moving in opposite directions. Owing to the greater ease of control in temperature and atmosphere the electric kiln yields first-class ware of a uniformity which cannot be obtained in a fuel-fired kiln. In spite of these advantages the progress made in the use of electricity has been very slow on account of the high cost of electric power. In America especially the general opinion is that electricity cannot compete with such low-priced fuels as oil or natural gas. The use of electricity for heating at low temperature (up to $1,000^{\circ} \mathrm{C}$.), for example, in decorating or enamelling kilns was introduced into Switzerland and Germany fifteen years ago.

After extensive research work and experimentation a number of electric tunnel kilns have been installed in Switzerland (since 1933) for the glazing of wall tiles, and for firing fireclay, soft porcelain and other goods requiring temperatures up to $1,300^{\circ} \mathrm{C}$. The first kiln for firing hard porcelain was put into operation at the Langenthal Factory in Switzerland in August 1937 and was constructed by Messrs. Brown, Boveri. The main novelty of this kiln, apart from the high temperature of $1,400^{\circ} \mathrm{C}$., is that part of the firing is conducted under a reducing oven atmosphere. Above $1,000^{\circ} \mathrm{C}$. the heating must be done under reducing conditions, as otherwise the small amounts 
of iron always present in the raw materials cause a yellowish-brown discoloration with a lowering of the transparency of the body mixture.

The Langenthal kiln is about 100 metres long with two tunnels, one for biscuit firing at $900^{\circ} \mathrm{C}$. and the other for sharp firing at $1,400^{\circ} \mathrm{C}$. The working experience of this kiln shows that apart from the smaller maintenance charges and high percentage of first-class ware obtainable, the savings in saggars is much more than the replacement charges on the elements. The writer concludes by saying that the success of the electric kilns can only be based on a proper combination of electrical engineering and ceramic knowledge.

\section{VIBRATION OF PROPELLER BLADES}

$\mathrm{E}$ ARLY in 1936, at the instigation of the National Physical Laboratory, the Singing Propeller Committee of the Institution of Naval Architects included among other recommendations in its report a proposed research on "the manner in which typical blades vibrate and the effect on vibration characteristics of changes in shape, thickness, etc." Some two years later the research was approved. by the Advisory Committee of the William Froude Laboratory.

One of the difficulties involved in the discussion of vibrating propellers has been the absence of any experimental knowledge of the modes of vibration of propeller blades. A few experiments were made by Mr. Harry Hunter, using a shaped flat plate of uniform thickness which was set in motion by 'bowing' it. This gave some patterns, but not frequencies. Tests with a single propeller blade having a flat driving surface have recently been published by Kerr, Shannon and Arnold. As before, the blade was held in a vice and vibrated by bowing the edge. Frequencies measured by tuning fork and mono-chord are given with their diagrams.

The method adopted to vibrate the blades in the present experiments was devised in conjunction with the Physics Department of the National Physical Laboratory, the apparatus being made and the experiments being carried out by E. J. Evans of that Department.

The model propellers were one foot in diameter, made with two blades on a heavy boss $2 \cdot 25$ in. in diameter and $3 \cdot 2 \mathrm{in}$. in length. The blades were made flat on the driving face, which was in a horizontal plane when secured to the base plate by a 1.25 in. diameter bolt and nut. The propeller plates were made flat on the driving face, which was in a horizontal plane when secured to the base plate. The method of exciting vibration of the blades was by an electromagnet with its pole tips just above the blade surface. The pole tips were about $\frac{1}{8}$ in. square and $\frac{1}{8} \mathrm{in}$. apart, so that the exciting force was applied over a small area of the blade. The magnet could be moved horizontally over the whole surface of one blade. It was supplied with alternating current from a beat-tone oscillator and amplifier. The frequency could be varied continuously over a range of about 50-11,000 cycles per second. In addition to the alternating current, the magnet was supplied with direct current through a separate pair of coils. In this way the magnet produced an alternating field of known frequency superimposed on a direct field.

To find the resonant frequencies of the propelfer, fine sand was sprinkled on the upper surface of the blades, and the exciting current was slowly varied through a given and known range of frequency. The resonance frequencies were detected by the loudness of the note emitted by the propeller, and by the sand on the blades taking a definite pattern, the sand usually moving towards the nodal regions. The magnet was moved about the blade in the tip region until the elearest diagram had been obtained on the blade under the magnet and the most intense note had been found. The frequency was then noted, the magnet removed, its position marked by a black dot, and a photograph of the sand pattern taken. A wide selection of these photographs are used to illustrate the paper.

Since the work was undertaken with a general idea of the results being applied to the problem of the singing propeller, it was desirable to know the range of frequencies which need to be studied for this purpose. The noise (if any) made by a bronze propeller about $18 \mathrm{ft}$. in diameter, propelling a ship in smooth water, is either a low-pitched hum with beats in it proportional to the number of blades and a frequency varying from 200 cycles per second to a somewhat higher figure; or a grinding noise or grunt with a maximum once per revolution of propeller, the major tone of which may vary from 200 to 300 c.p.s. Either or both of these may be present.

There are two principal modes of vibration which need to be considered, namely, (1) that in which the blade tip as a whole moves perpendicularly to the blade surface, which is referred to as flexural, and (2) that in which the blade twists from the boss about a more or less central line lying on its surface, referred to as torsional. Formulæ for a blade of parabolic outline, obtained by Conn, are given for these two kinds of vibration.

Although the two blades of any propeller were made alike within the normal limits of error for model work, it was found that actually they had slightly different resonant periods. The extreme figures obtained for the two blades for any mode of vibration are given. It is concluded that some of the variations must arise from variations in the metal of the two blades. Torsional and mixed resonance are also discussed and tables of extreme values of cycles per second are given.

A broad comparison of the results obtained with those given by others indicates that most of the patterns obtained by $\mathrm{H}$. Hunter are at too high a frequency to have much bearing on the singing propeller problem. The patterns shown in the paper by Kerr, Shannon and Arnold present some difficulties when compared with those in this paper. Possibly the difference arises from the fact that in these tests the exciting force was continuous and not a single strong burst of vibration. Twenty-five vibration patterns of propeller blades are shown. 